\title{
In vitro antioxidant activity studies of Artocarpus gomezianus
}

\author{
S.J. PRASHANTH ${ }^{1}$, D. SURESH*, V.H. POTTY ${ }^{1}$ AND P. SADANANDA MAIYA ${ }^{1}$
}

Department of Studies and Research in Chemistry, Tumkur University, TUMKUR (KARNATAKA) INDIA

Email : pdsuresh@gmail.com

${ }^{1}$ Dr. P. Sadananda Maiya Centre for Food Science and Research, BENGULURI (KARNATAKA) INDIA

Extraction of fruits, aerial parts and roots from Artocarpus gomezianus were subjected for pharmacognostic analysis. Also these parts were subjected tohydro-alcohol (30:70) extraction by soxhlet extraction technique. The raw materials were dried and powdered and analyzed for various parameters. The moisture content was found to be in the range of 4.97 per cent to 11.09 per cent, extractive values - 14.92 per cent to 18.75 per cent, chloroform solubility 1.15 per cent to 6.99 per cent and water solubility ranged between 4.52 per cent to 5.77 per cent. Fluorescence analysis and ash values were also determined. Extraction yields with 30:70 solvents indicate the quantitative idea about some of the proximate components. The results are important in planning the extraction, phytochemical analysis and determination of their various beneficial biological activities. The study was undertaken to evaluate qualitatively for the contents of carbohydrates, glycosides, saponins, alkaloids, flavonoids, phenolics, tannins, Phytosterols, Triterpenoids, oils and fats present in the extracts from the Fruit, Aerial parts and Roots of Artocarpus gomezianus. The extracts when tested qualitatively for various phytochemicals, they found to contain carbohydrates, Glycosides, alkaloids, tannins, phytosterols and Triterpinoids. However, they do not contain saponins, oils and fats. Quantitative estimation of extracts for total phenols and total flavonoids reveals that most parts contain reasonably higher amounts. The results clearly demonstrate that the extracts can be considered for further studies which evaluate the biological activity such as antioxidant activities. Antioxidant assays such as Nitric oxide scavenging assay, Ferric ion reducing activity assay, ABTS free radical scavenging activity assay and total antioxidant assays were performed to ascertain the potency of the extracts. Fruit extract of Artocarpus gomezianus was found to have maximum ferric ion reducing property than other parts studied. Nitric oxide scavenging activity was found to be higher in fruit followed by aerial and root parts. ABTS radical scavenging activity of aerial part extract is found to be $5 \mathrm{mg} / \mathrm{ml}$ compared to the standard ascorbic acid with $4 \mathrm{mg} / \mathrm{ml}$. The total antioxidant activity was found to be significantly high for the extract from fruit part than the extracts from aerial and root parts. It is clear from the studies that the extracts of aerial parts, fruits and roots possess potentially beneficial antioxidant activities. In view of their use in ancient medicine coupled with the recent understandings of these plant species, they may be considered for further exploration as they may yield very potent nutraceuticals.

Key words : Artocarpus gomezianus, Plant extracts, Antioxidant, Free radical scavenging

How to cite this paper : Prashanth, S.J., Suresh, D., Potty, V.H. and Maiya, P. Sadananda (2014). In vitro antioxidant activity studies of Artocarpus gomezianus. Asian J. Bio. Sci., 9 (2) : 273-283. 